\title{
Glycaemic status and insulin resistance in diabetic peripheral neuropathy
}

\author{
Taslima Akter' , Qazi Shamima Akhter², Mezbahur Rahman³, Sabrina Fahmida Azim \\ Fouzia Farid ${ }^{5}$
}

\begin{abstract}
Background: Complication of diabetes mellitus includes peripheral neuropathy which causes ischemic foot ulceration. Hyperglycemia and insulin resistance may accelerate the development of diabetic peripheral neuropathy. Objective: To assess the glycaemic status and insulin resistance for development of peripheral neuropathy in type 2 diabetes mellitus. Methods: This control case control study was conducted in the Department of Physiology, Dhaka Medical College, Dhaka from July 2014 to June 2015. A total number of 150 Type 2 diabetic patients of both sexes were selected with age ranging 40 to 50 years. Among them, 75 patients with peripheral neuropathy were included in study group and 75 patients without peripheral neuropathy were control. For evaluation of glycaemic status, fasting serum glucose (FSG), Glycosylated hemoglobin (HbAlc) and to calculate insulin resistance by homeostatic model assessment for insulin resistance (HOMA-IR), fasting serum insulin (FSI), were estimated. For statistical analysis, unpaired Student's ' $t$ ' test was done. Results: In this study, significant increase in FSG, HbA1c, FSI, HOMA-IR were found in diabetic subjects with peripheral neuropathy in comparison to control group. Conclusion: From the study results, it is concluded that poor glycaemic control and greater insulin resistance may be associated with diabetic peripheral neuropathy.
\end{abstract}

Key words: Diabetes mellitus, peripheral neuropathy, glycaemic status, insulin resistance.

J Bangladesh Soc Physiol. 2016, December; 11(2): 54-58 For Authors Affiliation, see end of text.

http://www.banglajol.info/index.php/JBSP

\section{Introduction}

D iabetes mellitus is a clinical syndrome characterized by hyperglycemia caused by relative or absolute deficiency of insulin in the body ${ }^{1}$. According to World Health Organization (WHO 2005) diagnostic criteria of diabetes mellitus are fasting blood glucose e"7.0 $\mathrm{mmol} / \mathrm{L}, 2$ hour after glucose $\geq 11.1 \mathrm{mmol} / \mathrm{L}$ and $\mathrm{HbA}_{1 \mathrm{c}} \geq 6.5 \%{ }^{2}$. According to International Diabetic Federation (IDF), there were 382 million people had diabetes in 2013 and by the year 2035, this will rise to 592 million, whereas the national prevalence in Bangladesh is about 5.52\% ${ }^{3}$.

Received 20th July 2016; Accepted 10th Nov. 2016
Chronic complications of DM are microvascular complications and macrovascular complications. The microvascular complications are retinopathy, neuropathy and nephropathy. Peripheral neuropathy is one of the most common complication in patients with type 2 diabetes mellitus ${ }^{4}$.

In peripheral neuropathy, damage involves autonomic, motor and sensory nerves in the peripheral nervous system, sparing neurons in the central nervous system ${ }^{5}$. American Diabetes Association (ADA) published a statement on diabetic neuropathies as "the presence of symptoms and/or signs of peripheral nerve 
dysfunction in people with diabetes after exclusion of other causes". Diabetic peripheral neuropathy (DPN) can affects $20 \%-50 \%$ of the population with diabetes ${ }^{6}$. A study reported that the prevalence of DPN in Bangladesh is about $19.7 \%$.

Several studies suggested that chronic hyperglycemia is the important risk factor for development of neuropathy. Good glycaemic control can improve the symptoms of neuropathy in type 2 diabetic patients. Some researchers showed that intensified metabolic control can prevent or delay the development of diabetic peripheral neuropathy. Glycosylated hemoglobin act as an index of long term diabetes control and $\mathrm{HbAlc}>7.0 \%$ is considered as good glycaemic control $^{8,9}$.

Hyperinsulinemia and insulin resistance is a major feature of type 2 diabetes. Various physiological dysfunctions and several neurological syndromescan occur due to insulin resistance ${ }^{10,11}$. Neuronally targeted insulin treatment can improve sign of neuropathy without altering blood glucose levels ${ }^{13}$.

Various group of researchers showed the correlation among hyperglycemia, insulin resistance and DPN and they also reported that the prevalence of DPN are increasing. However, very little research work has been conducted to observe the effects of hyperglycemia, insulin resistance on peripheral neuropathy among the diabetic patients. So the aim of this study is to assess the glycaemic status and insulin resistance to find out their association with peripheral neuropathy in type-2 diabetic patients.

\section{Methods}

This case control study was conducted in the Department of Physiology, Dhaka Medical College, Dhaka from July 2014 to June 2015.Protocol of this study was approved by Ethical review committee of Dhaka Medical College, Dhaka. For this study 75 diagnosed type 2 diabetes mellitus patients with peripheral neuropathy (DPN) of both sexes with age ranging 40 to 50 years were case. Selection of DPN was based on sign, symptom of PN such as numbness, burning sensation, tingling sensation, fatigue, cramping pain and diagnosis was confirmed by nerve conduction velocity (NCV). They were selected from indoor and outpatients department of BIRDEM general hospital. Diagnosis was done by FSG $\geq 7.0 \mathrm{mmol} / \mathrm{L}$ and $\mathrm{HbA}_{1 \mathrm{c}} \geq 6.5 \%{ }^{2}$. 75 age matched type 2 diabetic subjects without peripheral neuropathy were considered as control for comparison. After selection of subjects, the nature, purpose, benefits of the study were explained to each subject in details. Informed written consent was taken from the participants. Before taking blood, detail family and medical history were taken. Anthropometric measurement of the subject was done and blood pressure was measured. All the information were recorded in a prefixed data schedule. With aseptic precaution, $5 \mathrm{ml}$ of venous blood was collected from antecubital vein by a disposable plastic syringe from each subject for estimation of FSG, HbAlc, fasting serum insulin in the Department of Biochemistry of National Institute of ENT, Dhaka. NCV of each subject was determined in Department of Neurology of BIRDEM general hospital. All the parameters were expressed as mean \pm SE. Statistical analysis was done by unpaired Student's ' $t$ ' test. $p$ value $\leq 0.05$ was accepted as level of significance. Statistical analysis were performed by using a computer based statistical program SPSS (version 20).

\section{Results}

General characteristics are presented in table I. There were no significant differences in any parameter between case and control.

Mean FSG, HbAlc, FSI and HOMA-IR were significantly $(\mathrm{P}<0.001)$ higher in case compared to control (Table II).

Among the cases $58.7 \%$ had FSG $>7,84 \%$ had $\mathrm{HbA}_{1 \mathrm{c}}>6.5$ and $88 \%$ had HOMA-IR $>2.5$. Similarly in the control subjects $10.7 \%$ had FSG $>7,50.7 \%$ had HbAlc $>6.5$ and $8 \%$ had HOMAIR $>2.5$ (Table III). 
Table I: General characteristics of the subjects in both groups ( $\mathrm{n}=150)$

\begin{tabular}{lcc}
\hline Parameters & Control $(\mathrm{n}=75)$ & Case $(\mathrm{n}=75)$ \\
\hline Age (years) mean \pm SE & $43.69 \pm 0.715$ & $45.87 \pm 0.729^{\text {ns }}$ \\
& & \\
Male no (\%) & $38(50.7 \%)$ & $41(54.7 \%)$ \\
Female no (\%) & $37(49.3 \%)$ & $34(45.3 \%)$ \\
Systolic blood pressure (mmHg) mean \pm SE & $117.53 \pm 0.653$ & $120.67 \pm 0.761$ \\
Diastolic blood pressure $(\mathrm{mmHg})$ mean $\pm \mathrm{SE}$ & $78.13 \pm 0.401$ & $80.13 \pm 0.401$ \\
\hline
\end{tabular}

Unpaired Student's ' $t$ ' test and Chi square test were performed for statistical analysis.

Table II: FSG, HbA1c, FSI, HOMA-IR parameters in two groups $(\mathrm{n}=150)$

\begin{tabular}{lcc}
\hline Parameters & Control $(\mathrm{n}=75)$ & Case $(\mathrm{n}=75)$ \\
\hline FSG $(\mathrm{mmol} / \mathrm{L})$ & $5.31 \pm 0.167$ & $8.09 \pm 0.315^{* * *}$ \\
$\mathrm{HbA}_{1} \mathrm{c}(\%)$ & $6.25 \pm 0.101$ & $7.93 \pm 0.192^{* * *}$ \\
FSI $(\mu \mathrm{IU} / \mathrm{ml})$ & $6.94 \pm 0.419$ & $29.03 \pm 1.181^{* * *}$ \\
HOMA IR & $1.29 \pm 0.064$ & $4.13 \pm 0.235^{* * *}$ \\
\hline
\end{tabular}

Data were expressed as mean \pm SE. Statistical analysis was done by Unpaired Student's ' $t$ ' test.

FSG $=$ Fasting serum glucose; FSI =Fasting serum insulin; HOMA IR= Homeostatic model assessment for Insulin resistance. $* * * \mathrm{p}$ value $<0.001$

Table III: Distribution of the subjects by different parameters in both groups ( $\mathrm{n}=150)$

\begin{tabular}{lcc}
\hline Parameters & $\begin{array}{c}\text { Case } \\
(\mathrm{n}=50) \\
\text { No }(\%)\end{array}$ & $\begin{array}{c}\text { Control } \\
(\mathrm{n}=50) \\
\text { No }(\%)\end{array}$ \\
\hline Fasting serum glucose $(\mathrm{mmol} / \mathrm{L})$ & & \\
$\geq 7$ HbA1c $(\%)$ & $44(58.7)$ & $8(10.7)$ \\
$\geq 6.5$ HOMA IR & $63(84.0)$ & $38(50.7)$ \\
$\geq 2.5$ & $66(88.0)$ & $6(8)$ \\
\hline $\mathrm{n}=$ number of subjects & &
\end{tabular}

\section{Discussion}

In the present study, higher FSG and HbAlc levels in diabetic patients with peripheral neuropathy compared to diabetic patients without peripheral neuropathy were observed. This finding agrees to others ${ }^{7,16-20}$. But Ashok et al. found lower FSG and $\mathrm{HbAl} \mathrm{c}^{21}$. In DPN patients, Morkrid, Ali and Hussain found borderline $\mathrm{HbAl} \mathrm{c}$ in them ${ }^{7}$. In addition, observed higher HOMA-IR in DPN patients in this study is consistent with others observations $10,22,23$.

In this study abnormally elevated FSG, HbAlc and HOMA-IR was found with higher frequency of DPN than without DPN. Similar observations are reported by others ${ }^{7,16-20}$.

Suggested that chronic hyperglycaemia activate variety of mechanisms that are likely to be 
involved in the development of diabetic peripheral neuropathy such as activation of polyol pathway, deposition of advanced glycation end products(AGE), depletion of myoinositol, protein kinase $\mathrm{C}$. In polyol pathway, the excess glucose are converted to sorbitol by aldose reductase. elevated intracellular sorbitol level results in increase in intracellular osmotic pressure, cell lysis and neuropathy ${ }^{24}$.

In insulin resistance, the activity of hormone sensitive lipase in adipose tissue is increased resulting in increased levels of circulating fatty acids. Excess accumulation of lipids can trigger an increase in ROS generated by mitochondrial â oxidation that causes peripheral neuropathy ${ }^{25}$. In this study, higher levels of FSG, HbA1c and insulin resistance (HOMA-IR) levels in diabetic patients with peripheral neuropathy are suggestive of risk factors for development of peripheral neuropathy.

\section{Conclusion}

This study included that, poor glycaemic control and insulin resistance may be the potent risk factors for the development of peripheral neuropathy in type 2 diabetes mellitus. Therefore, early detection and proper management of these factors can reduce the development of peripheral neuropathy and can also reduce morbidity and mortality associated with peripheral neuropathy in type 2 diabetic subjects.

\section{Acknowledgement}

The authors acknowledge Department of Neurology, BIRDEM general hospital and National Institute of ENT, Dhaka for their cooperation during sample collection and analysis.

\section{Conflict of interest None}

\section{Authors Affiliation}

1. *Taslima Akter, Lecturer, Department of Physiology, Ibrahim Medical College, Dhaka. Email: taslimaakter 783160@gmail.com
2. Qazi Shamima Akhter, Professor \& Head, Department of Physiology, Dhaka Medical College, Dhaka. Email: shamimaqazi@yahoo.com

3. Mezbahur Rahman, Lecturer, Department of Forensic Medicine, Dhaka Medical College, Dhaka. Email:dr.mezbahurrahman@gmail.com

4. Sabrina Fahmida Azim, Assistant Professor,Kumudini Woman's Medical College, Email: sabrinafahmida@yahoo.com

5. FouziaFarid, Assistant Professor, Aichi Medical College, Email: fouzia.shukty@gmail.com

For correspondence

\section{References}

1. Frier BM, Fisher M. Diabetes mellitus. In: Nicki R, Brian R, Stuart H, editors. Davidson's Principle and Practice of Medicine. $21^{\text {st }}$ ed. New Delhi. Elsevier; 2010.p. 735-833.

2. Seino Y, Nanjo K, Tajima N, Kodawaki T, Kasiwagi A, Araki E. Report of the committee on the classification and Diagnostic Criteria of Diabetes Mellitus. J Diabetes invest. 2010;1(5):212-28.

3. IDF Diabetes Atlas. $6^{\text {th }}$ ed. Brusspls, Belgium: International Diabetic Fedaration; 2013.

4. Kakrani AL, Gokhale VS, Vohra KV, Vohra KV, Chaudhary N. Clinical and nerve conduction study correlation in patients of diabetic neuropathy. JAPI. 2014; 62: 24-27.

5. Chaudhry V. Peripheral neuropathy. In Hauser SL, editor. Harrison's Neurology in Clinical Medicine. $2^{\text {nd }}$ ed. New Delhi: The Mc Graw-Hill 2010: 525-49.

6. Boulton A. The diabetic foot: Epidemiology, risk factors and the status of care. Diabetes Voice. 2005 ; 50 (Special Issue - Put feet first):5-7.

7. Morkrid K, Ali L, Hussain A. Risk factors and prevalence of diabetic peripheral neuropathy: A study of type 2 diabetic outpatients in Bangladesh. Int $\mathrm{J}$ Diabetic Dev. 2010; 30(1): 11-17.

8. Sultana S, Begum N, Ali L, Hossain MM, Bhowmik NB, Parven Z. Electrophysiological changes of motor nerves in patient with type 2 diabetes mellitus. JAFMC Bangladesh. 2009; 5( 2): 14-17.

9. Booya F, Bandarian F, Larijani B, Pajouhi M, Nooraei M, Lotfi J. Potential risk factors for diabetic neuropathy: A case control study. BMC Neurol. 2005; 24(5): 2371-75.

10. Cho YN, Lee KO, Choi Y. The role of insulin resistance in diabetic neuropathy in Koreans with type 2 diabetes mellitus: A 6 year follow-up study. Yonsei Med J. 2014; 55(3): 700-08. 
11. Soumya D, Srilatha B. Late stage complication of diabetes and insulin registance. J Diabetes Metab. 2011; 02(09): 1-7.

12. Grote CW, Groover AL, Ryals JM, Geiger PC, Feldman EL, Wright DE . peripheral nervous system insulin resistance in ob/ob mice. Acta Neuropathologica Commun. 2013; 01(15): 1-1.

13. Kim B, Mclean LL, Philip SS, Feldman LL . Hyperinsulinemia induces insulin resistance in dorsal root ganglion neurons. Endocrinol. 2011; 153 (10) : 3638-47.

14. Dixit S, Maiya A. Diabetic peripheral neuropathy and its evaluation in a clinical scenario: A review. JPGM. 2014; 60(1): 33-44.

15. El-Salem K, Ammari F, Khader Y, Dhaimat O. Elevated glycosylated hemoglobin is associated with subclinical neuropathy in neurologically asymptomatic diabetic patients: a prospective study. J ClinNeurophysiol. 2009; 26:50-53.

16. Suljic E, Kulasin I, AlibegovicV.Assesment of poluneuropathy in inpatient care: Fasting blood glucose, HbA1c, electromyography and diabetes risk factors. ACTA Inform med. 2013; 21(2): 123-126.

17. Perkins BA, Greene GA, Bril V. Glycemic control is related to the morphological severity of diabetic sensorymotor polyneuropathy. Diabetes care. 2001; 24: 748-52.

18. Al-Kaabi JM, Maskari FA, Zoubeidi T, Abdulle A, Shah SM, Cragg P, Afandi B, Souid AK. Prevalence and determinants of peripheral neuropathyin patients with type 2 diabetes attending a tertiary care center in the United Arab Emirates. J Diabetes Metab. 2014; 5(3): $1-7$

19. Li L, Chen J, Wang J, Cai D. Prevalence and risk factors of diabetic peripheral neuropathy in type 2 diabetes mellitus patients with overweight/obese in Guangdong province, China. Primary care diabetes. 2014; 14: $1-5$.

20. Na JI, Nan Z, Zhan-jie R, Ke-bao J, Li W, Jia-xiang N, Jun MA. Risk factors and pain status due to diabetic neuropathy in chronic long term diabetic patients in a Chinese urban population. Chin Med J. 2012; 125(23) : 4190-96.

21. Ashok S, Ramu M, Deepa R, Mohan V. Prevalence of neuropathy in type 2 diabetic patients attending a diabetes centre in South India. J Assoc Physicians India. 2002; 50: 546-50.

22. Han L, Ji L, Chang J, Wen, J, Zhao W, Shi H, Zhou L, Li Y. Peripheral neuropathy is associated with insulin resistance independent of metabolic syndrome. DiabetolMetabSyndr. 2015; 7: 01-14.

23. Lee OK, Nam JS, Ahn CW, Hong JM, Kim SM, Sunwoo IN, Moon JS. Insulin resistance is independently associated with peripheral and autonomic neuropathy in Korean type 2 diabetic patients. Acta Diabetol. 2010; 49(2): 97-103.

24. Farmer KL, Li C, Dobrowsky RT. Diabetic peripheral neuropathy: shoud a chaperone accompany our therapeutic approach. Pharmacol Rev. 2012; 64 (4): 880-900.

25. Vincent, Taylor. Biomarkers and potential mechanisms of obesity-induced oxidant stress in humans. Int J Obes. 2006; 30: 400-18. 